\title{
Métodos Heurísticos aplicados na construção de roteiros de Transporte Escolar para o Estado do Paraná
}

\author{
Paulo Henrique Siqueira ${ }^{1}$ e Luzia Vidal de Souza ${ }^{2}$
}

\begin{abstract}
Resumo: Neste trabalho, o problema de roteirização de veículos é aplicado ao transporte escolar. A metodologia utilizada é composta de três fases: a primeira consiste na determinação de pontos de parada dos veículos, considerando uma distância máxima que os alunos podem andar de suas residências até estes pontos; na segunda são calculadas as distâncias reais a partir das informações das vias de cada município e na terceira as rotas são formadas aplicando a heurística Location Based Heuristic $(L B H)$ com algumas modificações para atender ao problema. Os testes foram realizados em 32 municípios do estado do Paraná. Os resultados obtidos foram comparados às rotas que são efetivamente realizadas em cada município, verificando-se uma economia que varia de 3,1 a 33,55\% na quilometragem total percorrida e no número de veículos utilizados, além de uma redução considerável na quantidade de pontos de parada dos veículos. DOI:10.4237/transportes.v20i3.567.
\end{abstract}

Palavras-chave: heurísticas de inserção, pesquisa operacional, transporte escolar.

\begin{abstract}
In this paper the vehicle routing problem is applied to school bus transportation. The presented methodology consists of three phases: the first one is to find the stops of the vehicles, considering the maximum distance that students can walk from their homes to these points; in the second one the real distances are calculated from information of the routes in each city and in the third one the routes are designed by applying heuristics Location Based Heuristic (LBH) with some modifications for adaptation to the real problem. The tests were accomplished for 32 cities in the state of Parana. The results were compared to routes that are actually performed in each city and it is possible to observe that there is an economy varying between 3.1 and $33.55 \%$ on total mileage traveled and in the number of used vehicles, besides a considerable reduction in the number of the vehicles stops.
\end{abstract}

Keywords: insertion heuristics, operations research, school bus transportation.

\section{INTRODUÇÃO}

As técnicas da Pesquisa Operacional possuem muitas aplicações na área de Transportes, pois além de melhorar a qualidade dos serviços de entrega e coleta, reduzem os custos de operação dos sistemas considerados. Uma aplicação importante é o problema do Transporte Escolar, que é um caso de roteirização de veículos com janelas de tempo (PRVJT) e frota heterogênea, além de entrega e coleta simultâneas. Nestes problemas, um conjunto de veículos faz serviços de coleta e/ou entrega aos consumidores em diversos pontos de uma região, com o objetivo principal de determinar um conjunto de rotas que satisfaçam a um dado conjunto de restrições, minimizando o custo total do sistema considerado (Bodin et al., 1983; Fisher, 1995; Lu e Dessouky, 2004).

O desenvolvimento de modelos matemáticos para o problema do transporte escolar (PTE) é um processo árduo e mesmo com um bom modelo, a sua solução é muito complexa, pois trata-se de uma classe de problemas que considera muitas restrições, elevando assim o custo computacional para a sua resolução. Desta forma, muitos esforços vêm sendo feitos por diversos pesquisadores na busca de técnicas heurísticas que possam oferecer boas soluções para o problema, com baixo custo computacional (Braca et al., 1997). As restrições impostas incluem a capacidade dos veículos, a distância máxima de cada rota, as janelas de tem-

${ }^{1}$ Paulo Henrique Siqueira, Departamento de Expressão Gráfica, Universidade Federal do Paraná, Curitiba, PR, Brasil. (e-mail: paulohs@ufpr.br).

${ }^{2}$ Luzia Vidal de Souza, Departamento de Expressão Gráfica, Universidade Federal do Paraná, Curitiba, PR, Brasil. (e-mail: luzia@ufpr.br).

Manuscrito recebido em 22/3/2012 e aprovado para publicação em $5 / 11 / 2012$. Este artigo é parte de TRANSPORTES v. 20, n. 3, 2012. ISSN: 2237-1346 (online). DOI:10.4237/transportes.v20i3.567. po, além da distância máxima permitida dos pontos de embarque até as respectivas casas dos alunos.

Neste trabalho foram aplicadas algumas técnicas da Pesquisa Operacional para oferecer uma solução para o problema do Transporte Escolar nos municípios do estado do Paraná. Utilizando a metodologia proposta, o gestor do Transporte Escolar de cada município tem condições de melhorar o atendimento aos alunos, reduzir o tempo de permanência dos mesmos dentro dos veículos, além de reduzir custos tanto no que se refere à quilometragem diária total, quanto no número total de veículos utilizados.

Os municípios do Estado do Paraná utilizam rotas com pontos de embarque mistos, ou seja, alunos de diferentes escolas podem ser designados à mesma rota. No PTE, os pontos de demanda são as residências dos alunos, e as restrições estão relacionadas à capacidade dos veículos e ao tempo máximo de permanência de cada aluno nos veículos, que neste caso, é limitado pela extensão máxima de cada rota.

Neste artigo apresenta-se uma estratégia de solução para o PTE do Estado do Paraná que está baseada em três etapas principais. A primeira consiste na determinação dos pontos de parada dos veículos (pontos de embarque), dada uma distância máxima que os alunos podem andar de suas residências até estes pontos. Na segunda etapa são determinadas as distâncias reais entre todos os pontos de embarque e desembarque (escolas). E na terceira etapa, a heurística Location Based Heuristic (LBH) (Bramel e Simchi-Levi, 1995) é utilizada com as devidas adaptações à situação real dos municípios do Estado do Paraná para definir as rotas dos veículos.

Este trabalho está dividido como segue. A segunda seção apresenta uma revisão da literatura sobre o problema de transporte escolar. Na Seção 3 é apresentada a metodologia 
de resolução do problema. Na Seção 4 são apresentados os experimentos realizados. E na Seção 5 são apresentados os resultados, bem como as conclusões.

\section{REVISÃO DA LITERATURA}

Nesta seção são apresentados alguns dos principais trabalhos publicados recentemente para solucionar o Problema de Roteirização de Veículos e o Problema de Transporte Escolar.

\subsection{Problema de roteirização de veículos}

O problema de roteirização de veículos é o processo utilizado para determinar os roteiros ou sequências de paradas que devem ser atendidos pelos veículos de uma frota, minimizando os custos para o atendimento do conjunto de pontos geograficamente dispersos. Cada ponto de demanda deve ser visitado apenas uma vez, respeitando a capacidade de cada veículo para cada rota e a extensão máxima da rota (Laporte et al., 2000).

Modares et al. (1999) mostraram como uma Rede Neural auto-organizável pode resolver tanto o problema dos Múltiplos Caixeiros Viajantes, quanto o problema de roteirização de veículos com restrições de capacidade. Os resultados obtidos são comparados com técnicas similares encontradas na literatura, e os resultados mostrados foram promissores.

Laporte et al. (2000) mostraram diversas técnicas utilizadas para resolver o problema de roteirização de veículos, incluindo técnicas tradicionais como savings de Clark e Wright, métodos de duas fases, e metaheurísticas como Busca Tabu. Foram apresentados resultados comparativos entre todas as técnicas mostradas no artigo, usando-se como parâmetros tanto o tempo computacional, quanto a qualidade de cada solução encontrada.

Os autores Toth e Vigo (2003) utilizaram a técnica de Busca Tabu Granular para resolver o problema de roteirização tradicional, aplicando a metodologia a vários conjuntos de dados encontrados na literatura e apresentando comparações dos resultados com outras técnicas.

Uma abordagem alternativa para o problema de entrega e coleta simultâneas com frota heterogênea é apresentada no trabalho de Lu \& Dessouky (2004). Este problema é formulado como um problema de programação inteira e resolvido pelos autores com um algoritmo branch-and-cut com 4 classes de desigualdades válidas da formulação matemática. Os autores mostraram que a técnica é capaz de determinar soluções ótimas para problemas com 5 veículos e 17 clientes.

A heurística ALNS (Adaptive Large Neighborhood Search), proposta por Ropke e Pisinger (2006a), foi aplicada a um conjunto de testes de problemas de entrega e coleta simultâneas considerando janelas de tempo e os resultados obtidos foram bons, reduzindo consideravelmente o tempo de percurso das rotas. A idéia básica desta técnica consiste na combinação de várias estratégias de inserção e remoção de pedidos em uma mesma heurística para obter melhores resultados. A técnica foi utilizada em uma base contendo 350 problemas com mais de 500 instâncias, apresentando resultados com melhoria em $50 \%$ dos problemas.

Em Ropke e Pisinger (2006b; 2007), os autores mostram a técnica de busca por vizinhança chamada ALNS (Adaptive Large Neighborhood Search) aplicada na resolução de 5 diferentes tipos de problema de roteamento de veículos: com janelas de tempo, capacitado, com múltiplos depósitos, dependente do local, no qual os clientes só podem ser atendidos por determinados tipos de veículos por causa dos acessos, e aberto, no qual os veículos não precisam retornar ao depósito. A heurística usa uma camada de inserção e remoção para intensificar a procura por soluções e foi aplicada a um conjunto de 338 problemas encontrados na literatura, para os quais obteve melhoria em 227 deles.

\subsection{Problemas de Transporte Escolar}

$\mathrm{Na}$ literatura são poucos os registros de trabalhos de aplicação da teoria de otimização ao PTE, para o qual se deseja obter um plano eficiente da programação de uma frota de veículos. No PTE, os veículos coletam os estudantes em seus pontos de parada e os entregam em suas respectivas escolas. Esta classe de problemas envolve diferentes subproblemas como a localização dos pontos de parada, geração das rotas dos veículos e ajustes do tempo das rotas em função do início das aulas.

Em Dulac et al. (1980), os alunos são designados para uma interseção de ruas adjacentes às ruas de suas residências, e um subconjunto destes pontos é considerado para resolver o problema tradicional de roteirização de veículos.

Em Bowerman et al. (1995) os autores apresentam uma formulação multi-objetivo para modelar o PTE, e apresentam um algoritmo heurístico que reduz a distância que os estudantes caminham de suas residências até os pontos de parada, além de minimizar os custos das rotas obtidas para visitar todos os pontos de parada.

No trabalho de Steiner et al. (2000) os autores abordam o PTE aplicado a um caso real. Primeiramente os pontos foram divididos em grupos (clusters), e em cada grupo foi gerada uma semente inicial que tinha a função do depósito. Foram criadas as rotas para cada grupo utilizando o algoritmo de construção de rotas de Clarke e Wright, e em seguida, foi aplicado o algoritmo de melhoria 2-opt na rota construída e entre as demais rotas. A economia obtida ficou em torno de $20 \%$ na quilometragem total percorrida diariamente.

Em Spasovic e Chien (2001) são apresentadas 3 técnicas para resolver o problema do transporte escolar da cidade de Riverdale em Nova Jersey: uma heurística de savings, um programa computacional denominado ROUTER e um método de troca de arcos. Os autores utilizaram os dados de 5 rotas com 2 veículos para comparar as técnicas, e o programa ROUTER apresentou os melhores resultados.

Li e Fu (2002) descreveram um estudo de caso do PTE, e apresentaram uma formulação multi-objetivo para o problema buscando minimizar o número total de veículos utilizados, o tempo total dos estudantes dentro dos veículos e a quilometragem total percorrida pela frota. Para solucionar o problema, os autores propuseram um algoritmo heurístico e obtiveram uma economia de $29 \%$ na distância total percorrida pela frota.

Schittekat et al. (2006) apresentam uma formulação de Programação Linear Inteira para resolver o problema de Transporte Escolar, com as devidas restrições de um município belga. Os autores consideram os pontos de parada potenciais e a alocação dos alunos às rotas como variáveis de decisão, além de soluções para pequenas instâncias.

No trabalho de Park e Kim (2010) os autores apresentaram uma revisão dos problemas de roteamento de veículos escolares, onde são apresentados alguns métodos para solu- 
ção do problema, tais como Simulated Annealing, Deterministic Annealing, Busca Tabu, Algoritmos Genéticos, Colônia de Formigas e Redes Neurais Artificiais. Os problemas são separados de acordo com suas principais características, tais como frota homogênea ou heterogênea, uma ou várias escolas, e a quantidade de períodos de atendimento.

No trabalho de Braca et al. (1997) os autores apresentaram uma metodologia para resolver o PTE da cidade de Nova York, e utilizaram o algoritmo Location Based Heuristic $(L B H)$ desenvolvido por Bramel e Simchi-Levi (1995). Os autores consideraram 838 pontos de parada e 73 escolas, onde o número mínimo de veículos determinado pelo algoritmo foi de 59 para o turno da manhã, e de 56 para o turno da tarde.

Como as restrições do PTE do Estado do Paraná são semelhantes às restrições apresentadas por Braca et al. (1997), o algoritmo LBH foi escolhido para encontrar as rotas do PTE do Estado do Paraná com algumas adaptações citadas a seguir.

O algoritmo $L B H$ mostrado em Braca et al. (1997) pode ser descrito através dos seguintes itens:

- frota homogênea;

- tem uma estrutura em laço (loop), com os seguintes passos para cada veículo $k$ :

- escolha aleatória de um ponto de parada $i$ não atendido;

- rota inicial: $R_{k}=\{i, \operatorname{escola}(i)\}$;

- enquanto o número de alunos de $R_{k}$ não exceder a capacidade dos veículos, são calculados os custos da inserção de todos os pontos $j$ não atendidos, variando-se a ordem de cada aluno $j$ e sua respectiva escola no vetor $R_{k}$; o ponto que possuir menor custo é inserido na rota $R_{k}$, com sua respectiva escola de destino;

- quando a rota possuir o número de alunos igual à capacidade dos veículos, a rota do veículo $k$ é finalizada, um outro veículo é escolhido, e o processo continua; e

- quando todos os pontos de parada possuem rotas designadas, as rotas construídas formam a solução do PTE.

As principais modificações realizadas no algoritmo $L B H$ de Bramel e Simchi-Levi (1995) para atender às características do PTE do Estado do Paraná são as seguintes:

- utilização de frota de veículos com capacidades variadas, começando a construção das rotas pelos veículos de maiores capacidades;

- verificação de ociosidade dos veículos ao final da construção de sua rota, e troca do mesmo por um outro, se for o caso;

- inicialização das rotas escolhendo-se o aluno não atendido que possuir ponto de parada mais distante de sua escola; e

- parâmetros de controle do tamanho da rota, que não permitem rotas muito extensas e nem rotas que atendam poucos alunos.

\section{METODOLOGIA}

Nesta seção é apresentada a metodologia utilizada para a solução do PTE do Estado do Paraná.

\subsection{Descrição do Problema Real}

No problema real a ser solucionado, estudantes do ensino fundamental e médio, que residem no interior do estado são transportados até suas respectivas escolas em seus períodos de estudo. O serviço de transporte é de responsabilidade das secretarias municipais de educação, e cada município é encarregado de designar a frota de veículos que será utilizada para fazer o transporte dos estudantes. Em geral estes veículos pertencem a empresas terceirizadas, e o custo é calculado por quilômetro rodado, de acordo com a frota utilizada.

As empresas que realizam os serviços de Transporte Escolar no estado do Paraná possuem frota heterogênea, mesmo porque existem regiões onde determinados veículos ficam impossibilitados de trafegar em função das condições das estradas, que em geral são muito íngremes e estreitas, tornando-se impossível o tráfego de veículos grandes. Assim, são contratados diversos tipos de veículos com diferentes capacidades. $\mathrm{O}$ banco de dados das cidades testadas neste trabalho não possui as informações sobre restrições de tráfego das vias, e possíveis restrições de tráfego não puderam ser consideradas, desta forma estas alterações de rotas, se necessárias, deverão ser feitas pelo gestor do transporte escolar.

Os alunos são coletados, levando-se em consideração a redução total do percurso do veículo, o que implica na redução do tempo de permanência dos estudantes no veículo e, além disso, estudantes das diversas séries e escolas são coletados na maioria das vezes na mesma rota.

Sendo assim, o PTE do Estado do Paraná pode ser formalmente descrito como segue. Considerando-se $v$ veículos para atender a demanda de $n$ alunos, os seguintes conjuntos de nós podem ser definidos:

- $N_{P}=\{1, . ., n\}$ : alunos em seus respectivos pontos de embarque (coleta);

- $N_{E}=\{n+1, . ., 2 n\}:$ pontos das escolas dos respectivos alunos (entrega);

- $\quad N_{P E}=\{1, \ldots, 2 n\}$ : conjunto de alunos e escolas (coleta e entrega);

- $A_{P E}: \operatorname{arcos}$ entre os nós de $N_{P E}$, desconsiderando-se os $\operatorname{arcos}(i+n, i)$ para $i \in N_{P}$, pois estes arcos violam a restrição de que o ponto de coleta deve estar antes do respectivo ponto de entrega;

- $N_{V}=\{2 n+1, . ., 2 n+v+1\}$ : conjunto dos veículos: $2 n+1$ representa o ponto de origem do veículo 1 ; $2 n+k$ representa o retorno do veículo $k-1$ e a origem do veículo $k$, onde $k=2,3, \ldots, v$; o nó $2 n+v+1$ representa o retorno do veículo $v$;

- $A_{V E}:$ arcos entre os nós de $N_{V}$ e $N_{E}$, desconsiderando-se o nó $2 n+1$, pois a origem do primeiro veículo da frota é o primeiro nó considerado na formação de uma solução factível;

- $A_{V P}$ : arcos entre os nós de $N_{V}$ e $N_{P}$, desconsiderando-se o nó $2 n+v+1$, pois o retorno do veículo $v$ é o último nó considerado na formação de uma solução factível;

- $A_{V}: \operatorname{arcos}$ entre os nós de $N_{V}$;

- $N=\{1, . ., 2 n+m+1\}$ : conjunto de todos os nós, e

- $A=A_{P E} \cup A_{E V} \cup A_{V P} \cup A_{V}$ : conjunto dos arcos considerados deste problema.

Com os seguintes coeficientes técnicos: 


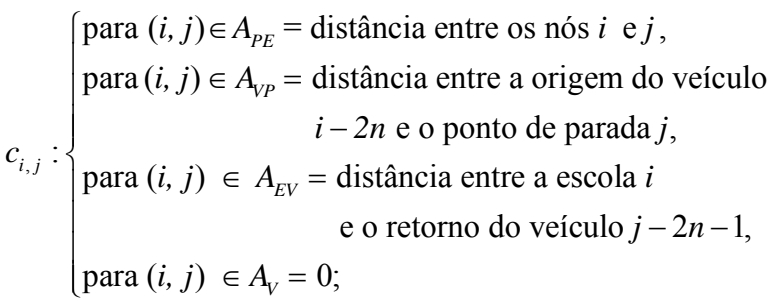

$M$ : maior distância permitida para cada veículo; $C_{k}$ : capacidade do veículo $k$;

As variáveis do problema são:

$$
\begin{gathered}
x_{i, j}=\left\{\begin{array}{l}
1, \text { se o arco }(i, j) \text { é usado na rota, } \\
0, \text { caso contrário; }
\end{array}\right. \\
b_{i, j}=\left\{\begin{array}{l}
1, \text { se o arco }(i, j) \text { é usado na } \\
\text { rota na ordem de } i \text { para } j, \\
0, \text { caso contrário }
\end{array}\right. \\
f_{i}= \begin{cases}C_{1} & i=2 n+1, \\
C_{i-2 n}-C_{i-2 n-1} & i=2 n+2, \ldots, 2 n+v, \\
0 & \text { caso contrário. }\end{cases}
\end{gathered}
$$

A formulação matemática para o PTE é apresentada a seguir. Esta formulação está baseada no trabalho de Lu e Dessouky (2004). Nesta aplicação a restrição (16) foi incluída para garantir que cada rota não ultrapasse o limite máximo de comprimento $M$.

Minimizar

$$
\sum_{i, j \in N} c_{i, j} x_{i, j}
$$

Sujeito a

$$
\begin{gathered}
\sum_{j \in N} x_{i, j}=1 \quad i \in N \\
\sum_{i \in N} x_{i, j}=1 \quad j \in N \\
b_{k, i} \leq b_{k, j}+1-x_{i, j} \\
\operatorname{para}(i, j) \in A /\{(2 n+v+1,2 n+1)\}, k \in N /\{i\} \\
\operatorname{para}(i, j) \in A /\{(2 n+v+1,2 n+1)\}, k \in N /\{i\} \\
b_{k, j} \leq b_{k, i}+1-x_{i, j} \\
b_{k, j} \leq b_{k, i}+1-x_{i, j} \quad i, j \in A /\{(2 n+v+1,2 n+1)\} \\
b_{i, i}=0 \quad i \in N \\
b_{n+i, i}=0 \quad i \in N_{p} \\
b_{i, n+i}=1 \quad i \in N_{p}
\end{gathered}
$$

$$
\begin{gathered}
b_{i, j}=b_{n+i, j} \quad i \in N_{P}, j \in N_{V} \\
1+\sum_{i \in N_{P}} b_{i, j}-\sum_{i \in N_{E}} b_{i, j} \leq \sum_{k \in N_{V}} f_{k} b_{k, j} \quad j \in N_{P} \\
b_{i, 2 n+1}=0 \quad i \in N \\
b_{k, j}=1 \quad j, k \in N_{V}, k<j \\
b_{j, k}=0 \quad j, k \in N_{V}, k<j \\
b_{i, 2 n+v+1}=1 \quad i \in N, i \neq 2 n+v+1 \\
\sum_{(i, j) \in A}\left(b_{k, j}-b_{k+1, j}\right) c_{i, j} x_{i, j} \leq M \quad k \in N_{V} \\
b_{i, j}=\{0,1\} \quad i, j \in N \\
x_{i, j}=\{0,1\} \quad(i, j) \in A
\end{gathered}
$$

A função objetivo (1) minimiza o custo total das rotas. As restrições (2) e (3) garantem que somente um veículo atende cada ponto de entrega ou coleta. As restrições (4) e (5) garantem que se $x_{i, j}=1$, o vértice $i$ é imediatamente anterior ao vértice $j$, forçando que $b_{k, i}=b_{k, j}$ para todo $k \in N$ e $k \neq i$. Neste caso, a restrição (6) força $b_{i, j}=1$, e a restrição (7) garante que $b_{i, i}=0$.

As restrições (8) e (9) garantem que o vértice de coleta (ponto de parada) será visitado antes do vértice correspondente de entrega (respectiva escola). A restrição (10) é de 'pareamento', que garante que o ponto de coleta será atendido pelo mesmo veículo que atenderá o respectivo ponto de entrega. A restrição (11) garante que em qualquer ponto da rota, a lotação de cada veículo não excederá sua respectiva capacidade. Em cada ponto de parada $j$ a capacidade do veículo será igual a $\sum_{k \in N_{V}} f_{k} b_{k, j}$, e após a visita ao vértice $j$ será igual a $1+\sum_{i \in N_{P}} b_{i, j}-\sum_{i \in N_{E}} b_{i, j}$.

A restrição (12) coloca a origem do primeiro veículo, cujo índice é $2 n+1$, designada para a primeira rota. As restrições (13) e (14) reforçam que os veículos entram na rota em sequência, onde a restrição (15) coloca o último nó das rotas como o ponto de retorno do último veículo da frota, cujo índice é $2 n+v+1$.

A restrição (16) garante que cada veículo $k$ não excede o limite máximo de comprimento das rotas $M$, pois quando $b_{k, j}-b_{k+1, j}=1$ o vértice $j$ (aluno ou escola) é atendido pelo veículo $k$, e o custo $c_{i, j}$ deve ser considerado para o cálculo do custo total da rota do veículo $k$. As restrições (17) e (18) são de integralidade das variáveis $x$ e $b$.

\subsection{Resolução do PTE do Estado do Paraná}

Para a resolução do problema foram consideradas as três etapas como citado anteriormente: $1^{\mathrm{a}}$ Determinação dos conjuntos de pontos de parada, $2^{\mathrm{a}}$ Determinação das distâncias entre os pontos, e $3^{\text {a }}$ Construção das rotas. Estas etapas estão descritas a seguir. 


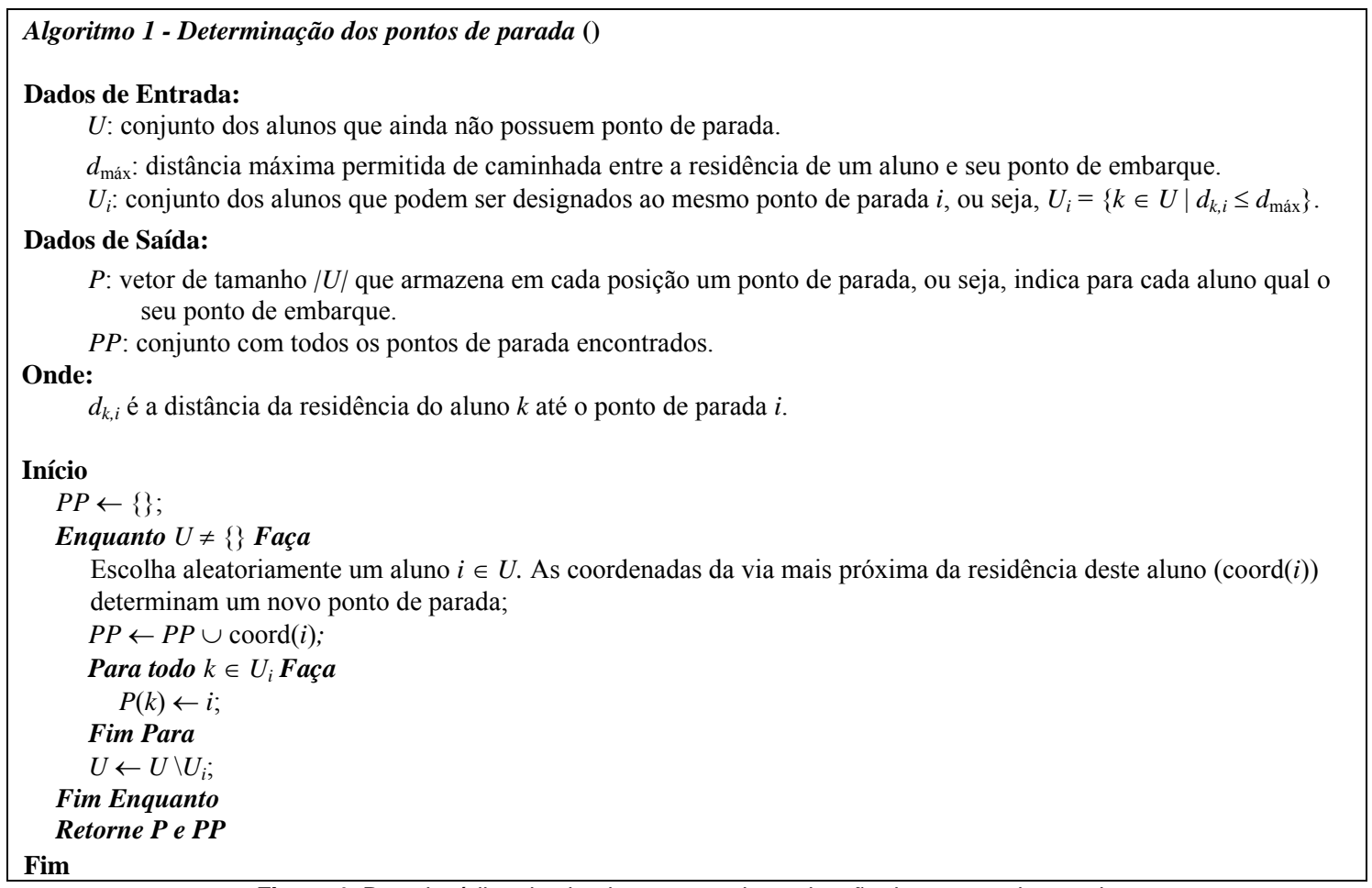

Figura 1. Pseudocódigo do algoritmo para a determinação dos pontos de parada

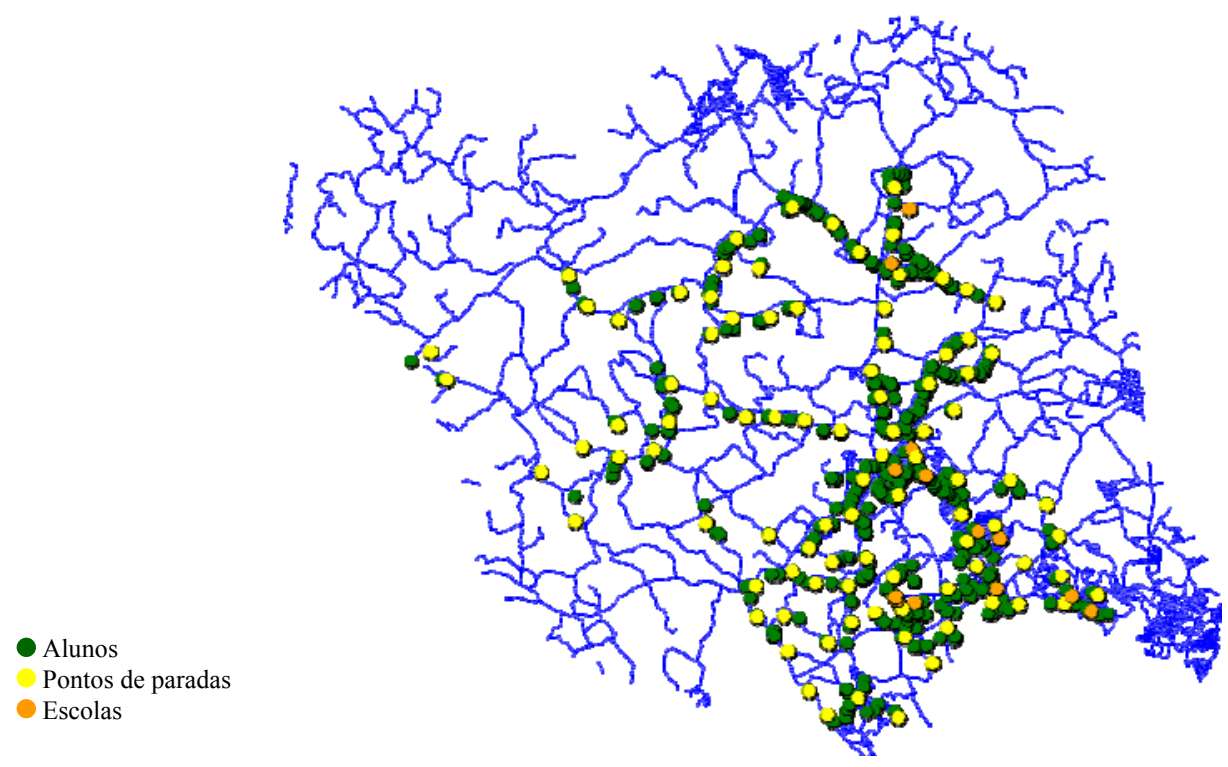

Figura 2. Mapa de Almirante Tamandaré com os pontos de parada e as escolas no turno da manhã

\subsubsection{1 $1^{a}$ Etapa: Determinação do conjunto dos pontos de parada}

Nesta etapa são definidos os pontos de parada (PP) de acordo com as posições geográficas dos pontos das residências dos alunos. Cada aluno deve ser designado ao ponto de parada mais próximo de sua casa. Nesta etapa definese a distância da casa do aluno até o ponto de embarque, que não deve exceder uma distância máxima permitida. No caso dos municípios do Paraná esta distância varia entre 500 e 3.000 metros. O algoritmo para a criação dos pontos de parada é descrito através do pseudocódigo apresentado na Figura 1.

Na Figura 2 estão representados os pontos de parada de- finidos pelo algoritmo mostrado na Figura 1, as posições geográficas das casas dos alunos e das escolas da cidade de Almirante Tamandaré para o turno da manhã, onde $d_{\max }=$ 1.500 metros. Antes da construção das rotas é necessário calcular as distâncias reais entre os pontos da rota, ou seja, entre os PP's e dos PP's às escolas. Pelo fato de não existirem mapas digitalizados para estes municípios, foi necessária a construção destas vias de acesso com os dados fornecidos pela Secretaria Estadual de Desenvolvimento Urbano do estado do Paraná (SEDU). Estes dados contêm as coordenadas geográficas dos pontos das vias de cada município de 100 em 100 metros, bem como as informações de cruzamentos entre vias e de finais de vias. De posse destes dados foi possível construir o mapa viário que fornece uma 
Tabela 1. Número de pontos dos mapas das cidades testadas do Paraná [Fonte: SEDU-PR]

\begin{tabular}{|c|c|c|c|}
\hline Município & Número de pontos do mapa & Município & Número de pontos do mapa \\
\hline Abatia & 7.228 & Londrina & 46.635 \\
\hline Agudos do Sul & 8.758 & Maringá & 25.930 \\
\hline Almirante Tamandaré & 10.857 & Medianeira & 11.818 \\
\hline Ampère & 14.546 & Nova Prata do Iguaçu & 15.901 \\
\hline Apucarana & 24.034 & Ortigueira & 50.478 \\
\hline Araruna & 11.567 & Pitanga & 39.647 \\
\hline Araucária & 21.342 & Ponta Grossa & 54.031 \\
\hline Bom Jesus do Sul & 10.508 & Prudentópolis & 54.533 \\
\hline Campo Largo & 32.255 & Quatro Barras & 7.620 \\
\hline Castro & 43.793 & Rio Negro & 24.618 \\
\hline Chopinzinho & 30.507 & Santa Amelia & 3.973 \\
\hline Cianorte & 13.390 & Santa Helena & 15.113 \\
\hline Cruz Machado & 37.127 & Santa Mariana & 11.834 \\
\hline Guaratuba & 14.721 & São Mateus do Sul & 31.194 \\
\hline Lapa & 46.958 & Toledo & 36.805 \\
\hline Loanda & 9.344 & Tunas do Paraná & 12.268 \\
\hline
\end{tabular}

diversidade de caminhos que puderam ser explorados na busca de melhores soluções para o problema. A construção destes mapas é uma tarefa complexa, pois existem muitas informações, tornando o processo lento. Para exemplificar, pode-se citar que a base de dados para o mapa do município de Prudentópolis contém 54.533 pontos que, juntamente com os pontos de parada e com os pontos de escola, formam a base de dados completa do município e para esta base deve-se calcular as distâncias. Na Tabela 1 encontram-se as quantidades de pontos dos mapas das 32 cidades utilizadas.

\subsection{2. $2^{a}$ Etapa: Determinação das distâncias entre os pontos}

Embora o custo computacional para o cálculo das distâncias reais seja muitas vezes superior ao custo de se utilizar a distância euclidiana, e por se tratar da solução de um problema real, estes cálculos tornam-se indispensáveis. Para ilustrar o problema que ocorre ao se utilizar a distância euclidiana, é apresentado um exemplo que ocorreu na base de dados de um dos municípios. Neste caso, a distância euclidiana entre dois pontos escolhidos é igual a 2,5 quilômetros, porém, por tratar-se de uma região de difícil acesso, a distância real entre estes pontos chega a pouco mais de 97 quilômetros (Figura 3), ou seja, a distância real é igual a aproximadamente 39 vezes mais que o valor da distância euclidiana.

Os algoritmos de Floyd e Dijkstra (Taha, 1997) podem ser utilizados para o cálculo das distâncias mínimas reais, cujas ordens de complexidade algorítmicas são $\mathrm{O}\left(n^{3}\right)$ e $\mathrm{O}\left(n^{2}\right)$, respectivamente, enquanto que as distâncias euclidianas exigem $\mathrm{O}(1)$. Como o número de pontos dos mapas é relativamente grande, e as distâncias entre os PP's e entre os PP's e as escolas não envolvem todos os pontos do mapa da cidade, optou-se pela utilização de um algoritmo guloso para calcular a distância real entre cada par de pontos $(I, J)$,

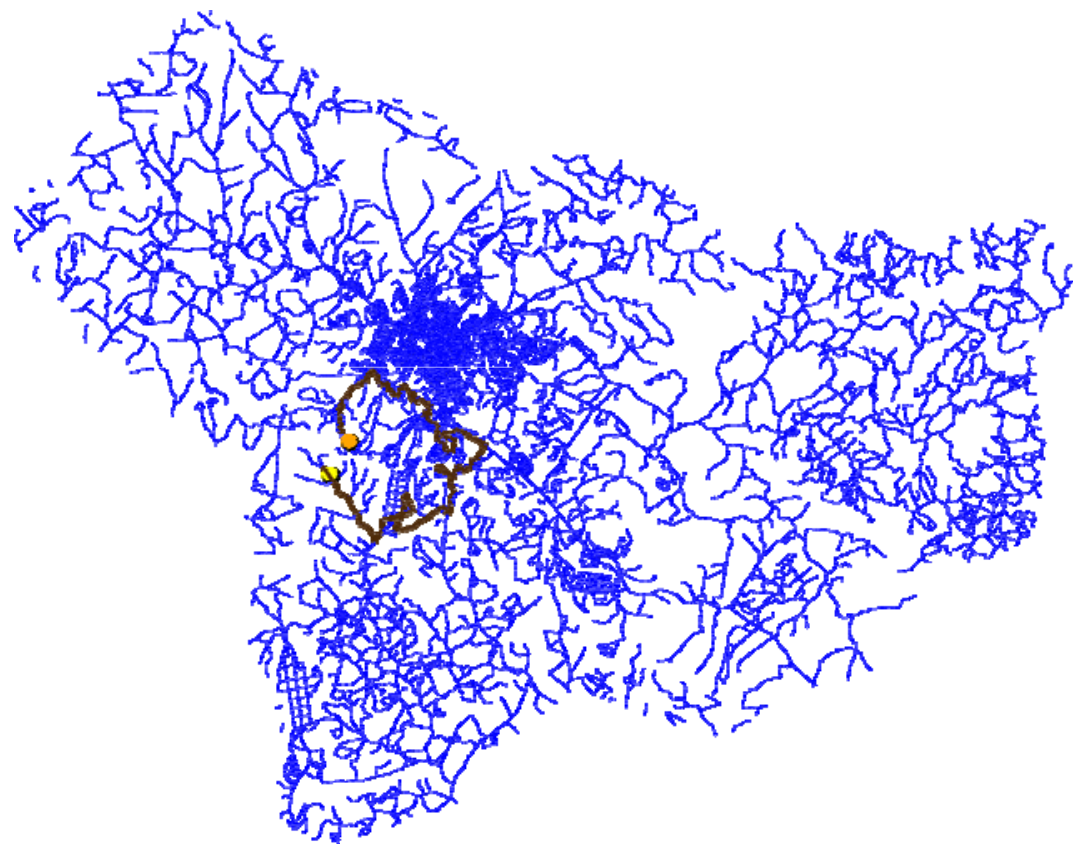

Figura 3. Mapa de Ponta Grossa - distância real entre as extremidades da rota é 39 vezes maior que a distância euclidiana entre o ponto inicial e final 


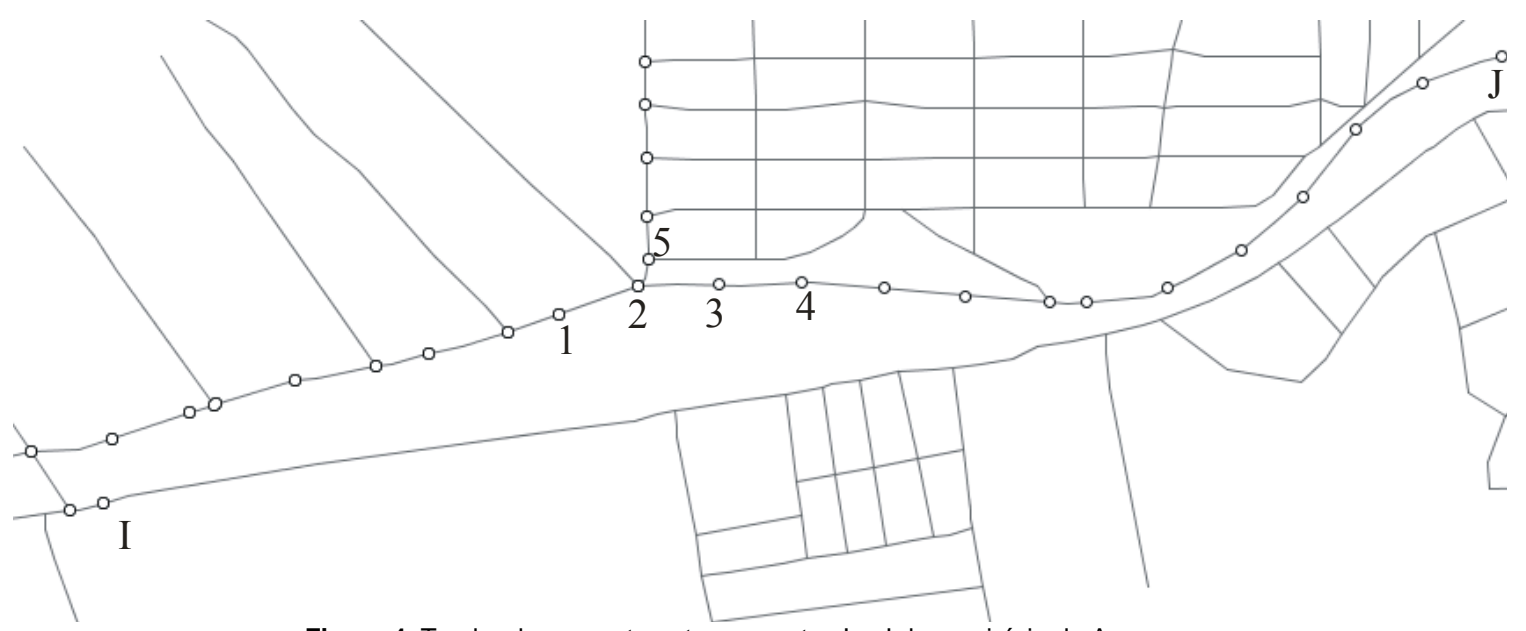

Figura 4. Trecho de uma rota entre os pontos I e J do município de Apucarana

que explora apenas as distâncias entre os cruzamentos das vias próximas de $I$ e $J$. No caso da utilização de algoritmos como Floyd ou Dijkstra, todos os pontos do mapa devem ser considerados para a busca do melhor caminho possível entre $I$ e $J$, exigindo maior esforço computacional.

A base de dados que foi construída para representar as vias de acesso que gerou um conjunto $A_{I}$ de pontos vizinhos de um ponto $I$, e o conjunto $T_{k}$ de pontos situados em um mesmo trecho de uma via $k$, onde um trecho é definido como o conjunto de pontos entre dois cruzamentos. Na Figura 4 é apresentado um exemplo da construção do banco de dados com as rodovias que podem ser utilizadas. Neste exemplo mostra-se uma sub-rota entre os pontos $I$ e $J$ da cidade de Apucarana, em que o ponto 2 representa um cruzamento entre duas vias, e o conjunto dos pontos vizinhos é $A_{2}=\{1,3,5\}$, o que significa que partindo do ponto 2 há possibilidade de seguir em direção aos pontos 1,3 ou 5 , o que não ocorre com o ponto 3 , cujo conjunto $A_{3}$ possui apenas dois elementos, $A_{3}=\{2,4\}$, ou seja, partindo do ponto 3 é possível seguir para o ponto 4 ou retornar para o ponto 2. Vale ressaltar que o exemplo mostrado foi para um cruzamento simples, porém foram considerados pontos com até seis cruzamentos, onde cada cruzamento representa uma possibilidade de um novo caminho a ser considerado no processo de otimização de rotas.

$\mathrm{O}$ algoritmo guloso proposto para calcular a menor distância entre dois pontos possui ordem de complexidade algorítmica variável, pois analisa somente os pontos com cruzamentos próximos aos pontos $I$ e $J$. Em todos os casos tem-se a ordem de complexidade menor do que $\mathrm{O}\left(n^{2}\right)$, e o pseudocódigo do algoritmo é apresentado na Figura 5.

\subsection{3. $3^{a}$ Etapa: Construção das rotas - LBH - Location Ba- sed Heuristic}

Após ter sido feita a designação dos alunos para os pontos de parada e calculadas as distâncias entre os pontos de parada e escolas, inicia-se o processo de construção das rotas com o algoritmo $L B H$ adaptado.

O pseudocódigo do algoritmo utilizado encontra-se descrito na Figura 6, onde as distâncias utilizadas são reais, calculadas através do algoritmo mostrado na Figura 5. A função c_rota(.) do algoritmo calcula a distância total do trecho de rota com a inserção de um aluno $i$ e sua respectiva escola, variando as posições dos elementos inseridos até que se encontre a menor distância possível. A função ro- ta(.) insere o aluno $k$ e sua escola na melhor posição definida pela função $c \_r o t a\left(\right.$.). A função $t \_r o t a($.$) calcula as dis-$ tâncias reais entre cada par de pontos das rotas, resultando no comprimento total da rota.

Os termos $n_{1}$ e $n_{2}$ foram inseridos para auxiliar a técnica $L B H$ como parâmetros de controle, com as seguintes funções: o termo $n_{1}$ permite maiores rotas quando o número de lugares nos veículos for menor do que a demanda de alunos; o termo $n_{2}$ é usado para evitar rotas muito longas, além de proibir que o tamanho máximo da rota seja igual à distância de um ponto de parada até uma escola. $\mathrm{O}$ algoritmo LBH é aplicado separadamente para cada turno, e a quilometragem total diária para cada veículo é calculada através das viagens de ida e volta, passando por cada ponto de embarque e desembarque da rota construída.

$\mathrm{O}$ algoritmo proposto neste trabalho utiliza as diferentes capacidades $C_{v}$ dos veículos, além de iniciar a construção de cada rota com o aluno mais distante de sua escola e com veículos de maior capacidade.

Após escolher o veículo com maior capacidade que ainda não possui rota e o aluno mais distante de sua escola, o algoritmo faz sucessivas inserções de alunos e suas respectivas escolas, utilizando a função c_rota(.), até atingir o limite máximo da capacidade do veículo $C$ ou do comprimento da rota $M^{*}$. Cada inserção é feita levando-se em conta a factibilidade da rota em três pontos principais: não excedendo a capacidade do veículo escolhido; não permitindo comprimento maior do que o limite $M^{*}$; e inserindo um aluno sempre antes de sua respectiva escola.

Ao escolher um aluno em seu ponto de embarque $P(j)$, a função $c \_r o t a($.) determina a melhor posição deste ponto no vetor de atendimento da rota. Se a escola do aluno $j$ não estiver na rota, o algoritmo deve definir também a melhor posição da escola neste vetor da rota. O objetivo desta verificação da função $c \_r o t a($.) é de verificar qual inserção factível de cada rota será mais econômica.

O parâmetro $M^{*}$ utilizado no Algoritmo 3 permite rotas maiores do que o limite $M$ quando a distância do ponto de embarque do aluno $j$ for maior que $M$, ou quando a proporção entre o total de alunos e o total de lugares disponíveis da frota for maior do que 1 , com o objetivo de atender o máximo possível de alunos do conjunto $N_{A}$. Se o ponto de embarque de um aluno $j$ estiver a uma distância maior do que $M$ até a sua escola, então este parâmetro $M^{*}$ amplia o 


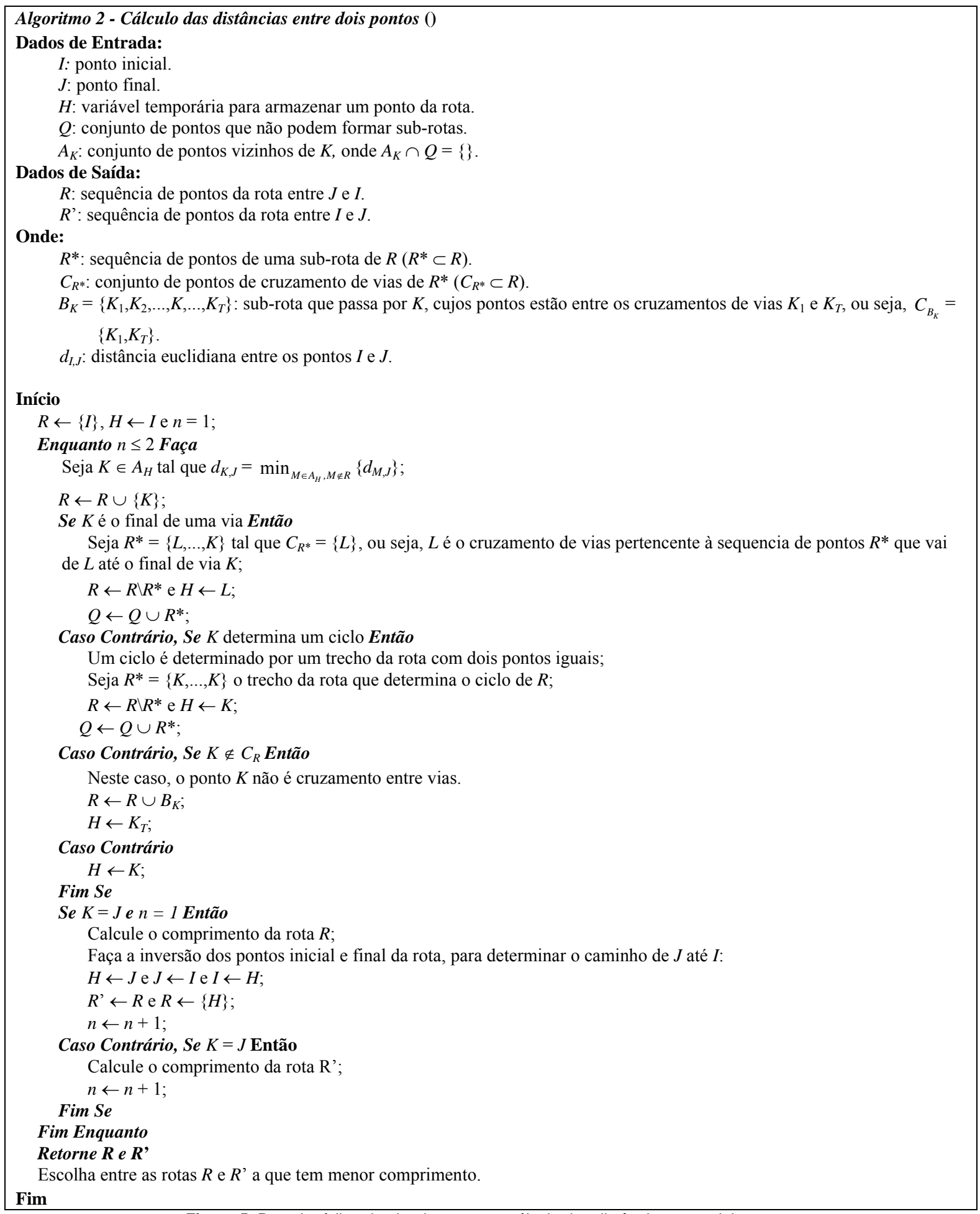

Figura 5. Pseudocódigo do algoritmo para o cálculo das distâncias entre dois pontos

limite do comprimento desta rota com o objetivo de evitar que esta rota atenda somente o aluno $j$.

Quando não for mais possível inserir alunos e escolas em uma rota, seja por ultrapassar a capacidade do veículo ou a extensão máxima da rota, o algoritmo encerra a rota e faz uma avaliação da mesma. Trata-se de uma modificação proposta no algoritmo original da técnica $L B H$, verificando se o veículo da rota que acabou de ser construída possui ociosidade e fazendo a troca deste veículo por outro menor que ainda não tem rota. Esta modificação visa minimizar a ociosidade do veículo designado para cada rota.

\section{EXPERIMENTOS REALIZADOS}

Os experimentos foram realizados com as bases de dados de trinta e dois municípios do estado do Paraná, são eles: Abatiá, Agudos do Sul, Almirante Tamandaré, Ampère, Apucarana, Araruna, Araucária, Bom Jesus do Sul, Campo Largo, Castro, Chopinzinho, Cianorte, Cruz Machado, Guaratuba, Lapa, Loanda, Londrina, Maringá, Medianeira, 


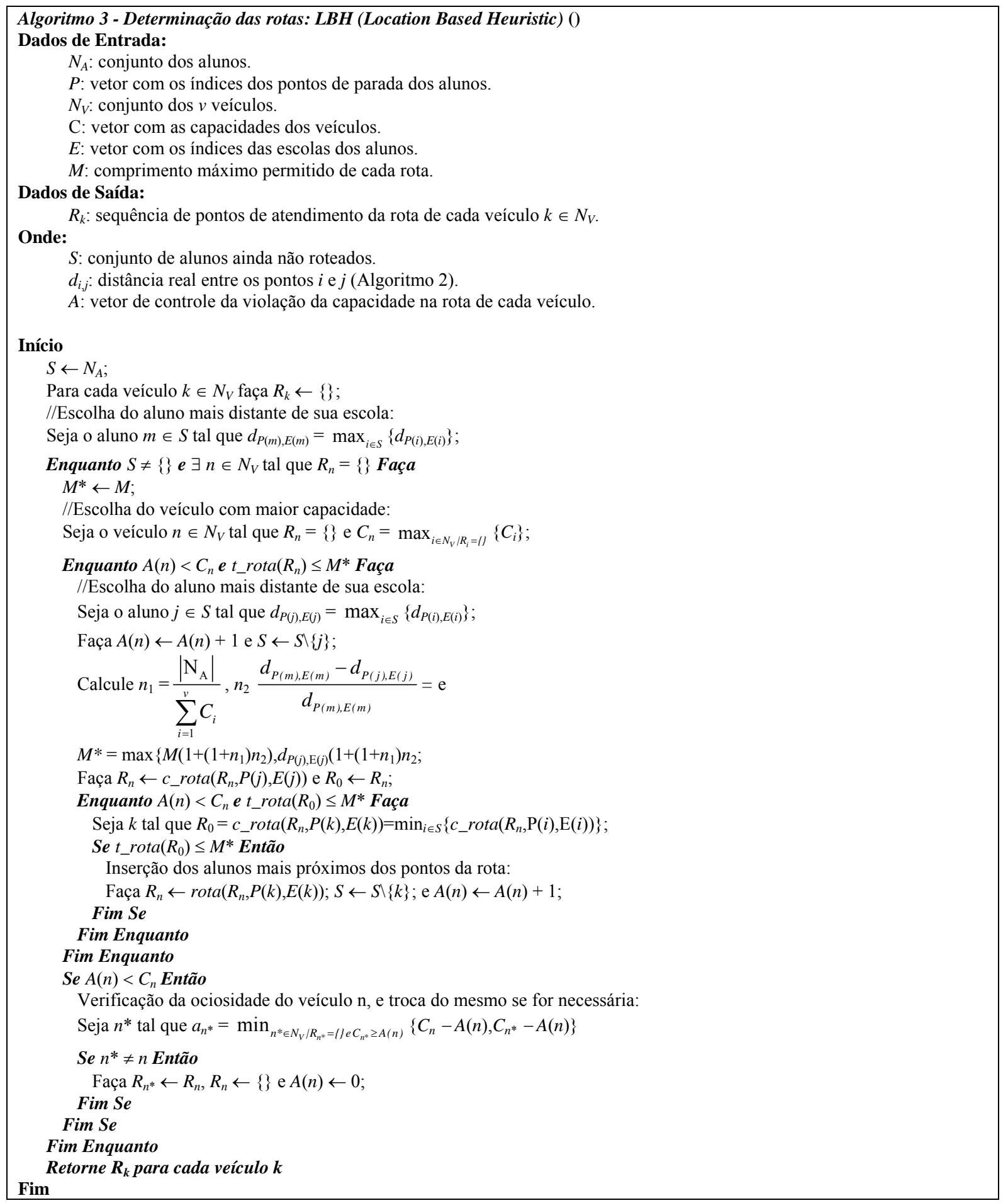

Figura 6. Pseudocódigo do algoritmo para a determinação das rotas

Nova Prata do Iguaçu, Ortigueira, Pitanga, Ponta Grossa, Prudentópolis, Quatro Barras, Rio Negro, Santa Amélia, Santa Helena, Santa Mariana, São Mateus do Sul, Toledo e Tunas do Paraná. Estes dados foram disponibilizados pela Secretaria de Educação do Estado (SEED) e pela Secretaria de Desenvolvimento Urbano (SEDU) do Paraná.

Os resultados foram comparados aos obtidos com o auxílio de um aparelho de GPS (Global Positioning System), utilizado para o mapeamento das rotas do Transporte Escolar que são efetivamente realizadas em cada município. Es- te estudo das rotas foi feito através do levantamento das coordenadas dos pontos de embarque e desembarque dos alunos de cada cidade, com o registro da quilometragem total e do veículo designado para cada rota.

Os veículos utilizados nestas cidades podem ser classificados em 4 tipos: Peruas, com capacidades que variam entre 8 e 12 lugares; Vans, com capacidades de 15 lugares; Microônibus, com capacidades que variam entre 20 e 32 lugares; e Ônibus, com capacidades que variam entre 35 e 75 lugares. Na Tabela 2 são apresentados os dados de cada 
Tabela 2. Dados das escolas, dos alunos que utilizam o Transporte Escolar, e dos veículos disponíveis [Fonte: SEDU-PR]

\begin{tabular}{|c|c|c|c|c|c|c|c|c|}
\hline \multirow[b]{2}{*}{ Município } & \multirow[b]{2}{*}{ Alunos } & \multirow[b]{2}{*}{ Escolas } & \multirow{2}{*}{$\begin{array}{l}\text { Média dist. } \\
\text { escolas e } \\
\text { alunos (m) }\end{array}$} & \multicolumn{5}{|l|}{ Veículos } \\
\hline & & & & Peruas & Vans & Micro-ônibus & Ônibus & Capac. total \\
\hline Abatia & 210 & 8 & 7.372 & - & - & 3 & 8 & 449 \\
\hline Agudos do Sul & 641 & 8 & 4.780 & 2 & 1 & 2 & 8 & 454 \\
\hline Almirante Tamandaré & 4.589 & 24 & 3.412 & 5 & - & 3 & 30 & 1.536 \\
\hline Ampère & 775 & 18 & 5.822 & 2 & 2 & 1 & 12 & 550 \\
\hline Apucarana & 2.285 & 89 & 5.287 & 31 & 11 & - & 17 & 1.104 \\
\hline Araruna & 828 & 9 & 6.328 & 5 & - & - & 8 & 416 \\
\hline Araucária & 2.440 & 33 & 7.713 & - & 22 & 18 & 40 & 2.557 \\
\hline Bom Jesus do Sul & 471 & 8 & 6.848 & 3 & 1 & - & 7 & 326 \\
\hline Campo Largo & 3.322 & 54 & 8.616 & 50 & 7 & - & 51 & 2.808 \\
\hline Castro & 4.504 & 49 & 11.318 & 11 & 10 & 2 & 29 & 1.569 \\
\hline Chopinzinho & 1.911 & 24 & 5.494 & 4 & - & 8 & 24 & 1.263 \\
\hline Cianorte & 1.455 & 34 & 7.206 & 1 & 4 & 11 & 13 & 968 \\
\hline Cruz Machado & 1.923 & 19 & 8.979 & 16 & 4 & 13 & 26 & 1.563 \\
\hline Guaratuba & 1.605 & 25 & 7.481 & - & - & 1 & 25 & 1.136 \\
\hline Lapa & 2.160 & 44 & 10.509 & 6 & 2 & 2 & 13 & 758 \\
\hline Loanda & 297 & 17 & 7.844 & 4 & 1 & 1 & 3 & 180 \\
\hline Londrina & 2.291 & 160 & 12.740 & 25 & 18 & 14 & 48 & 3.435 \\
\hline Maringá & 653 & 103 & 4.556 & 6 & 4 & 5 & 8 & 606 \\
\hline Medianeira & 1.316 & 32 & 5.047 & 5 & 3 & 2 & 21 & 1.011 \\
\hline Nova Prata do Iguaçu & 899 & 9 & 7.854 & 1 & - & 5 & 9 & 538 \\
\hline Ortigueira & 1.567 & 32 & 12.031 & 43 & 2 & 6 & 9 & 955 \\
\hline Pitanga & 1.778 & 28 & 8.911 & 41 & - & 5 & 22 & 1.486 \\
\hline Ponta Grossa & 1.407 & 165 & 12.686 & 14 & 1 & 12 & 32 & 1.942 \\
\hline Prudentópolis & 1.818 & 72 & 7.529 & 20 & 4 & 7 & 35 & 1.918 \\
\hline Quatro Barras & 1.963 & 7 & 5.355 & 4 & - & 3 & 13 & 687 \\
\hline Rio Negro & 821 & 30 & 6.056 & 7 & 2 & 1 & 18 & 960 \\
\hline Santa Amelia & 99 & 5 & 3.570 & 1 & 3 & - & - & 57 \\
\hline Santa Helena & 1.159 & 17 & 7.030 & 7 & 2 & 3 & 22 & 1.123 \\
\hline Santa Mariana & 216 & 23 & 8.027 & 5 & - & - & 7 & 400 \\
\hline São Mateus do Sul & 2.509 & 47 & 7.310 & 17 & 1 & - & 44 & 2.146 \\
\hline Toledo & 2.297 & 88 & 7.938 & 6 & 3 & 7 & 31 & 1.689 \\
\hline Tunas do Paraná & 627 & 4 & 9.683 & - & - & - & 8 & 296 \\
\hline média & $1.588,6$ & 40,2 & $7.541,6$ & 12,2 & 4,9 & 5,6 & 20,3 & 1.135 \\
\hline
\end{tabular}

um dos municípios referentes às quantidades de alunos que utilizam o Transporte Escolar, de escolas, de veículos disponíveis e das médias das distâncias entre os alunos e suas escolas.

Para exemplificar os resultados obtidos, as Figuras 7 e 8 apresentam os mapas com as rotas construídas para o município de Almirante Tamandaré para os períodos da manhã e da tarde, respectivamente. Nas Figuras 9, 10 e 11 são mostradas as rotas criadas para os 3 turnos (manhã, tarde e noite) das cidades Nova Prata do Iguaçu, Santa Helena e Ampère, respectivamente, e as rotas obtidas levantadas com o auxílio do GPS. Nestas análises, a maior distância utilizada entre os pontos de parada dos alunos é $d_{\text {máx }}=1.500$ metros, com atendimento de todos os alunos da cidade. Nestes mapas, nota-se uma grande redução nas quantidades de números de parada.

A aplicação da metodologia apresentada neste trabalho proporcionou uma economia para estes municípios que varia entre $3,1 \%$ e $33,55 \%$ na quilometragem total diária, conforme mostrado na Tabela 3. Outros dados mostrados nesta tabela são as maiores distâncias $M$ para cada rota, conside- radas como parâmetro para cada cidade e que variam entre 20 e 60 km, e as médias das distâncias percorridas das residências dos alunos até seus respectivos pontos de embarque, que variam entre 197 e 353 metros. A distância máxima considerada entre os pontos de parada para todas as cidades foi $d_{\text {máx }}=1.500$ metros. A tabela mostra ainda o tempo computacional total para executar as três etapas da metodologia.

Com a possibilidade de simular várias combinações dos parâmetros de comprimento máximo de cada rota, da distância entre os pontos de parada e da área de abrangência das escolas, os gestores de Transporte Escolar de cada município podem definir quais parâmetros serão capazes de fornecer melhores resultados para o PTE, de acordo com a realidade de seu município. A escolha destes parâmetros tem grande influência no processo de otimização, algumas delas podem ser citadas: se a maior rota definida for muito pequena, ou seja, inferior a 20 quilômetros, haverá uma demanda maior na quantidade de veículos, enquanto que rotas mais extensas fazem com que o tempo de permanência dos estudantes nos veículos seja maior. 
Pontos de paradas Escolas

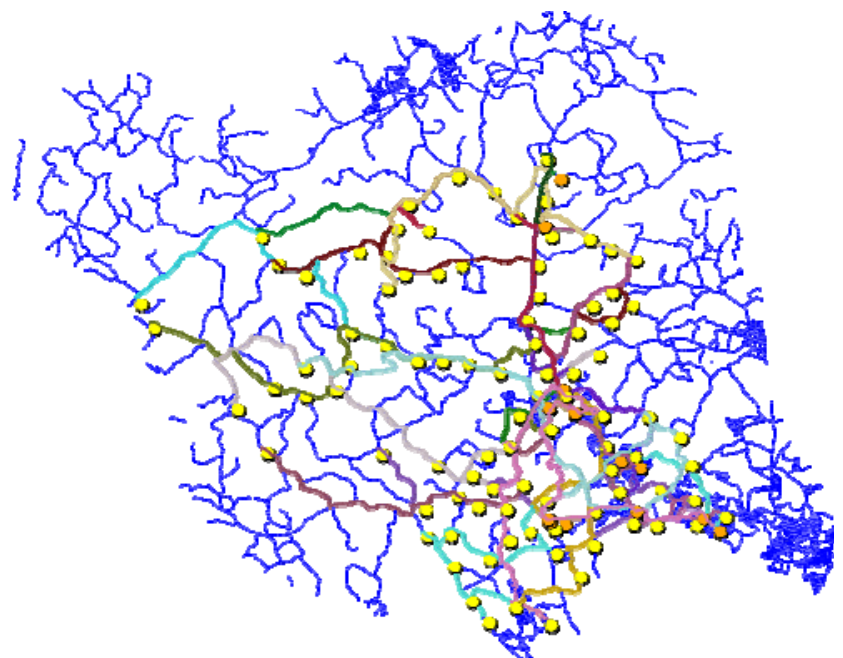

Figura 7. Mapa de Almirante Tamandaré com as rotas do turno da manhã

Pontos de paradas

Escolas

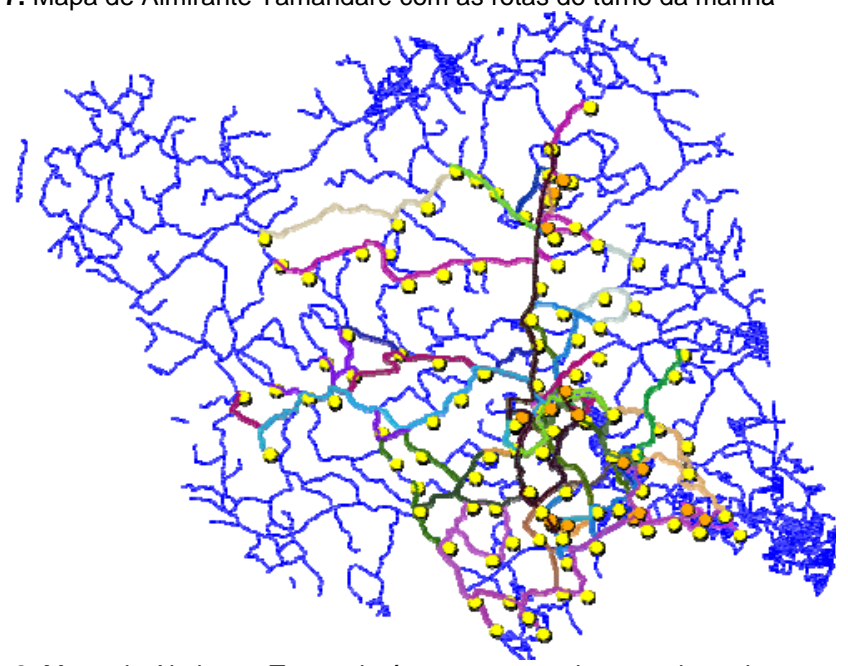

Figura 8. Mapa de Almirante Tamandaré com as rotas do turno da tarde

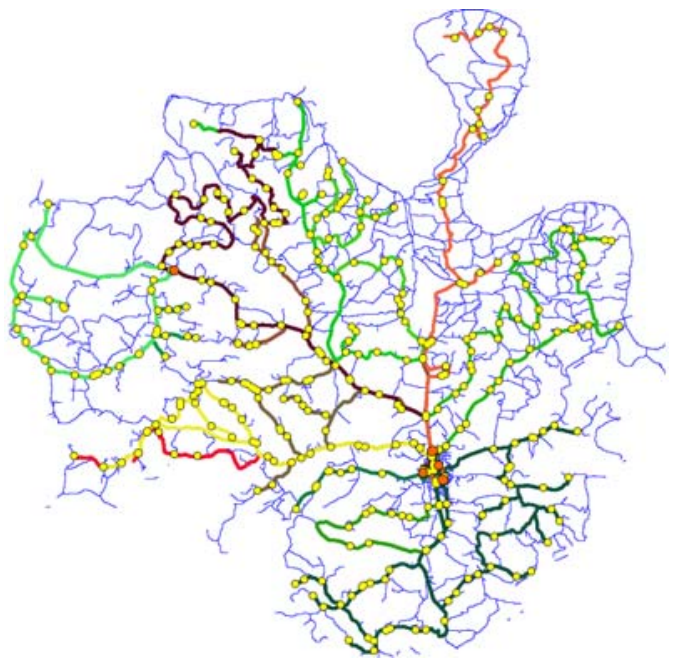

(a)

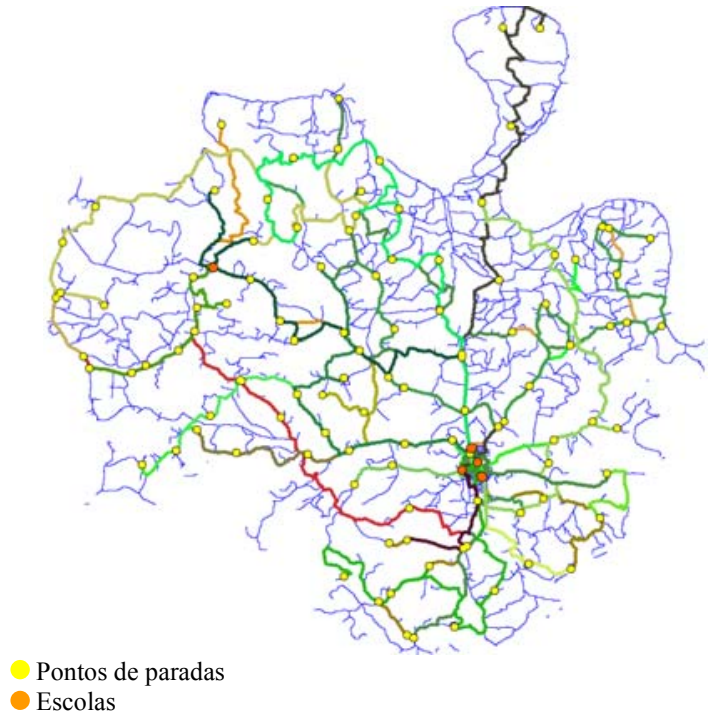

(b)

Figura 9. Mapa de Nova Prata do Iguaçu com as rotas dos 3 turnos com (a) GPS e (b) LBH 


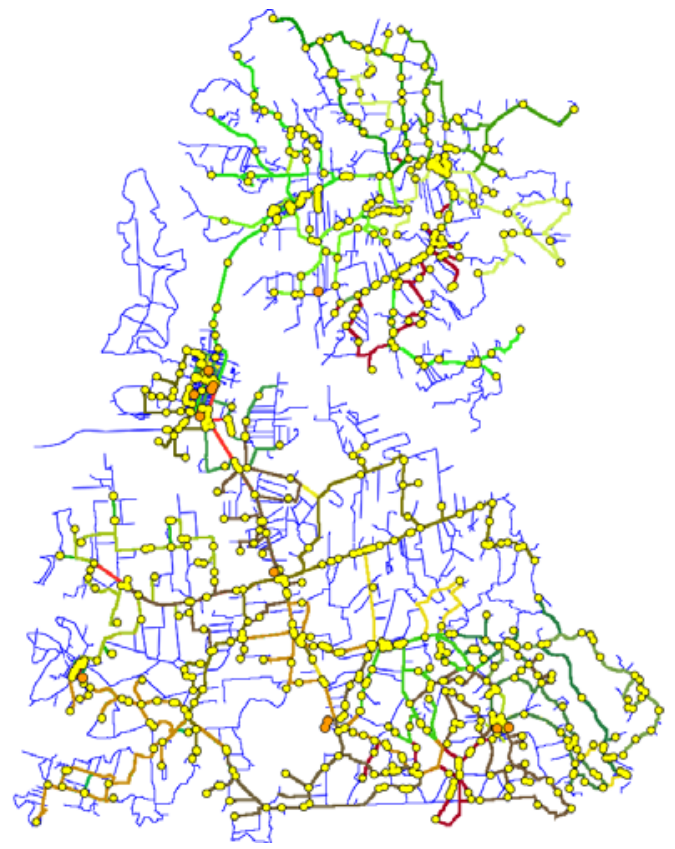

(a)

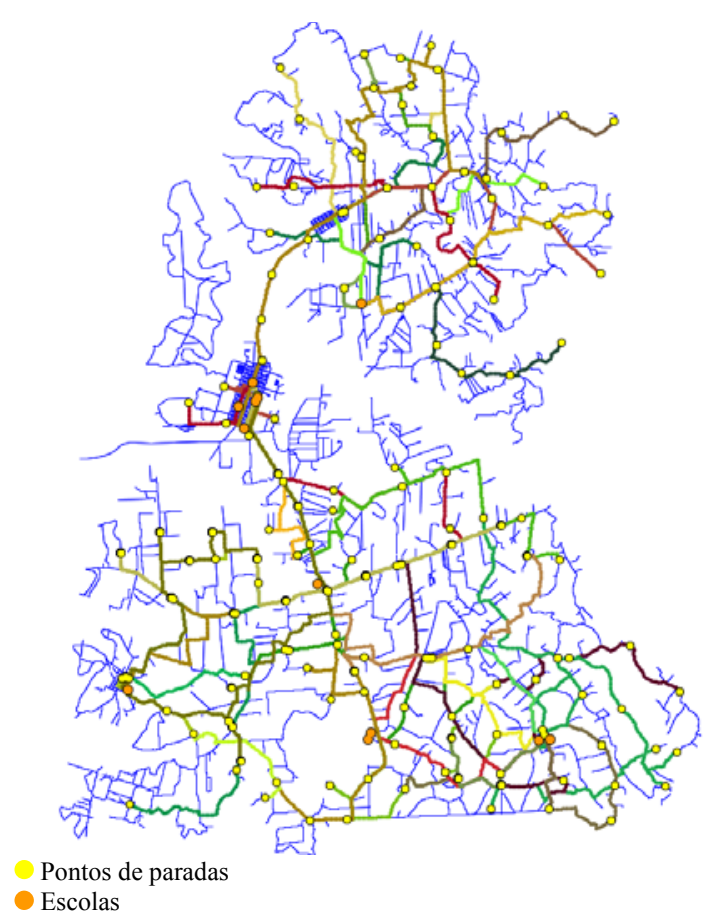

(b)

Figura 10. Mapa de Santa Helena com as rotas dos 3 turnos com (a) GPS e (b) $L B H$

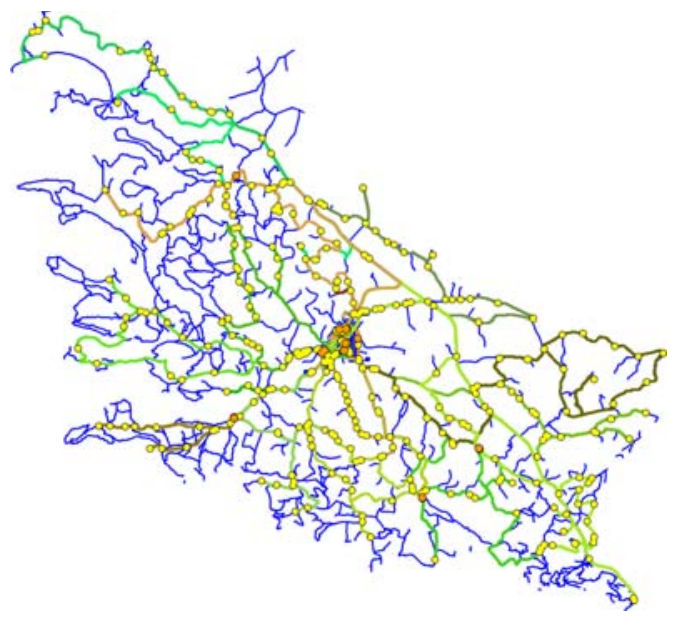

(a)

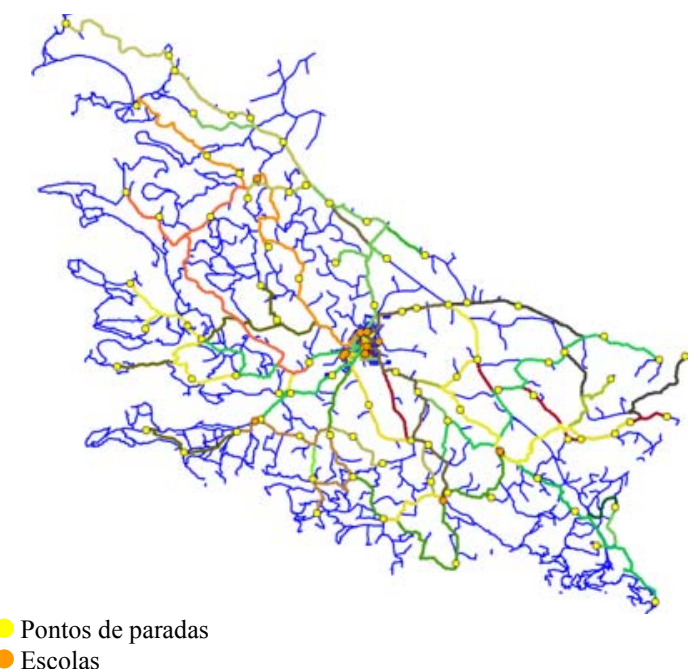

(b)

Figura 11. Mapa de Ampère com as rotas dos 3 turnos com (a) GPS e (b) LBH

\section{CONCLUSÕES}

Neste trabalho foi apresentada uma metodologia para a resolução do problema de roteirização do Transporte Escolar para os municípios do estado do Paraná. A solução deste problema foi realizada em três etapas: determinação dos pontos de parada, o cálculo das distâncias entre os pontos de parada e escolas, e a aplicação do algoritmo $L B H$ adaptado para a construção das rotas. Como mostra a Tabela 3, trata-se de uma metodologia eficiente, pois além de apresentar uma economia que varia entre $3,1 \%$ e $33,55 \%$ na quilometragem total das rotas das trinta e duas cidades mostradas, reduz consideravelmente o número de pontos de parada dos veículos, evitando que os veículos façam muitas paradas e aumentem o tempo da rota. Outra melhoria obtida foi na redução da quantidade de veículos utilizados para atender às demandas das cidades.

No que se refere ao tempo computacional, pode-se observar que apesar dos bancos de dados possuírem um número considerável de registros, não se trata de um processo demorado, como se pode ver na Tabela 3. Em média, as três etapas da metodologia levam 7.125 segundos para serem concluídas. Os testes foram realizados em um compu- 
tador comum, com processador Pentium IV, de $2.8 \mathrm{GHz}$ e $1 \mathrm{~Gb}$ de memória RAM. Os dados da cidade de Castro demoram em torno de 12 a 16 horas de processamento, enquanto que a menor cidade testada, Santa Amelia, tem seus dados processados entre 3 e 5 segundos. Vale ressaltar que os tempos computacionais mostrados referem-se às três fases completas da metodologia proposta e que os resultados são obtidos para os três turnos: manhã, tarde e noite. Além disso, este processo será executado duas vezes ao ano, no início do ano letivo e no meio do ano, pois é neste período que ocorrem as grandes mudanças no Transporte Escolar dos municípios. O processo de inserção ou exclusão de um aluno da rota durante este período deve ser realizada manualmente, caso contrário acarretaria numa mudança geral de todas as rotas para preservar o processo de otimização.

Como a realidade dos municípios paranaenses não difere muito da realidade dos demais estados brasileiros, esta metodologia pode ser facilmente aplicada em outros municípios, minimizando-se assim os custos com o Transporte Escolar. Com a possibilidade de mudanças dos parâmetros das distâncias entre pontos de parada e a criação de uma área de abrangência das escolas, o gestor de Transporte Escolar de cada município pode adequar esta metodologia à realidade de seu município.

\section{REFERÊNCIAS BIBLIOGRÁFICAS}

Bodin, L.; B. Golden; A. Assad e M. Ball (1983) The state of the art in the routing and scheduling of vehicles and crews. Computers \& Operations Research, v. 10, n. 2, p. 63-211. DOI:10.1016/03050548(83)90030-8.

Bowerman, R.; B. Hall e P. A. Calamai (1995) A Multi-Objective optimization approach to urban school bus outing: formulation and solution method. Transportation Research, v. 29A, n. 2, p. 107-123. DOI: 10.1016/0965-8564(94)E0006-U.

Braca, J.; J. Bramel; B. Posner e D. Simchi-Levi (1997) A computerized approach to the New York City school bus routing problem. IIE Transactions, v. 29, n. 8, p. 693-702. DOI:10.1023/A: 1018526202990 .

Bramel, J. e D. Simchi-Levi (1995) A location based heuristic for general routing problems. Operations Research, v. 43, n. 4, p. 649-660. DOI:10.1287/opre.43.4.649.

Dulac, G.; J. Ferland e P. A. Fogues (1980) School bus routes generator in urban surroundings. Computers \& Operations Research, v. 7, p. 199-213. DOI:10.1016/0305-0548(80)90006-4.

Fisher, M.L. (1995) Vehicle routing. Handbooks in Operations Research and Management Science: Network Routing, v. 8, p. 1-33. DOI:10.1016/S0927-0507(05)80105-7.

Laporte, G.; M. Gendreau; J. Y. Potvin e F. Semet (2000) Classical and modern heuristics for the vehicle routing problem. International Transactions in Operational Research, v. 7, n. 4-5, p. 285-300. DOI:10.1111/j.1475-3995.2000.tb00200.x.

Li, L.Y.O. e Z. Fu (2002) The school bus routing problem: a case study. Journal of the Operational Research Society, v. 53, n. 5, p. 552558. DOI:10.1057/PALGRAVE/JORS/2601341.

Lu, Q. e M. Dessouky (2004) An Exact algorithm for the Multiple Vehicle Pickup and Delivery Problem. Transportation Science, v. 38, n. 4, p. 503-514. DOI:10.1287/trsc.1030.0040.

Modares, A.; S. Somhom e T. A. Enkawa (1999) A self-organizing neural network approach for multiple traveling salesman and vehicle routing problems. International Transactions in Operational Research, v. 6, n. 6, p. 591-606. DOI:10.1111/j.1475-3995.1999. tb00175.x.

Park, J. e B. I. Kim (2010) The school bus routing problem: A review. European Journal of Operational Research, v. 202, n. 2, p. 311319. DOI:10.1016/j.ejor.2009.05.017.

Ropke, S. e D. Pisinger (2006a) An Adaptive Large Neighborhood Search Heuristic for the Pickup and Delivery Problem with Time Windows. Transportation Science, v. 40, p. 455-472. DOI:10.1287/ trsc. 1050.0135 .

Ropke, S. e D. Pisinger (2006b) A unified heuristic for a large class of Vehicle Routing Problems with Backhauls. European Journal of
Operational Research, v. 171, n. 3, p. 750-775. DOI:10.1016/ j.ejor.2004.09.004.

Ropke, S. e D. Pisinger (2007) A general heuristic for vehicle routing problems. Computers \& Operations Research, v. 34, n. 8, p. 2403-2435. DOI:10.1016/j.cor.2005.09.012.

Schittekat, P.; M. Sevaux e K. Sorensen (2006) A mathematical formulation for a school bus routing problem. Anais do ICSSSM'06: International Conference on Service Systems and Service Management, França, p. 1552-1557. DOI:10.1109/ICSSSM.2006. $\underline{320767 .}$.

Secretaria Estadual de Desenvolvimento Urbano do Estado do Paraná SEDU/PR. Disponível em: <http://www.paranacidade.org.br/>. (Acesso em 30/03/2012).

Secretaria de Estado da Educação - SEED/PR. Disponível em: $<$ http://www.seed.pr.gov.br/> (Acesso em 30/03/2012).

Spasovic, L. e S. Chien (2001) A Methodology for Evaluating of School Bus Routing - A Case Study of Riverdale, New Jersey. Anais do $80^{\text {th }}$ Annual Meeting of Transportation Research Board, Washington.

Steiner, M.T.A.; L. V. Z. Zamboni; D. M. B. Costa; C. Carnieri e A. L. Silva (2000) O Problema de roteamento no Transporte Escolar. Pesquisa Operacional, v. 20, n. 1, p. 83-99. DOI:10.1590/ S0101-74382000000100009.

Taha, H.A. (1997) Operations research: an introduction $\left(6^{\text {th }}\right.$ ed.), Prentice Hall, New Jersey.

Toth, P. e D. Vigo (2003) The Granular Tabu Search and Its Application to the Vehicle-Routing Problem. INFORMS Journal on Computing, v. 15, n. 4, p. 333-346. DOI:10.1287/ijoc.15.4.333.24890. 
Tabela 3. Resultados da aplicação da técnica LBH para 32 municípios do Paraná

\begin{tabular}{|c|c|c|c|c|c|c|c|c|c|}
\hline Município & Veíc. & Técnica & $\begin{array}{l}\text { Pontos de } \\
\text { parada }\end{array}$ & $\begin{array}{l}\text { Veículos } \\
\text { utilizados }\end{array}$ & km total & $\begin{array}{l}\text { Economia } \\
(\%)\end{array}$ & $\begin{array}{l}\text { M: maior } \\
\text { rota }(\mathrm{km})\end{array}$ & $\begin{array}{l}\text { Média dist. até } \\
\text { os PP's (km) }\end{array}$ & $\begin{array}{l}\text { Tempo } \\
\text { de CPU } \\
\text { (seg.) }\end{array}$ \\
\hline \multirow{2}{*}{ Abatiá } & \multirow{2}{*}{11} & GPS & 285 & 11 & 776.681 & \multirow{2}{*}{26,87} & \multirow{2}{*}{20} & \multirow{2}{*}{0,321} & \multirow{2}{*}{151} \\
\hline & & LBH & 97 & 11 & 568.006 & & & & \\
\hline \multirow{2}{*}{ Agudos do Sul } & \multirow{2}{*}{13} & GPS & 375 & 12 & 1.010 .382 & \multirow{2}{*}{19,66} & \multirow{2}{*}{30} & \multirow{2}{*}{0,243} & 163 \\
\hline & & $\mathrm{LBH}$ & 76 & 11 & 811.790 & & & & 103 \\
\hline Almirante & 27 & GPS & 2.207 & 27 & 2.711 .020 & 640 & 30 & 0330 & 52730 \\
\hline Tamandaré & 21 & LBH & 321 & 27 & 2.535 .028 & 0,49 & 30 & 0,339 & 52.130 \\
\hline Amnère & 17 & GPS & 450 & 17 & 1.309 .028 & 1616 & & 0109 & \\
\hline Ampere & 17 & LBH & 103 & 15 & 1.097 .432 & 16,16 & 20 & 0,199 & 442 \\
\hline Apucaran & 50 & GPS & 1.128 & 59 & 2.613 .291 & 803 & 40 & 0302 & 3087 \\
\hline Apucarana & 39 & $\mathrm{LBH}$ & 309 & 26 & 2.379 .818 & 0,93 & 40 & 0,302 & 3901 \\
\hline Araruna & 13 & GPS & 446 & 13 & 1.769 .158 & 2087 & 50 & 0340 & 3644 \\
\hline Araruna & 13 & LBH & 134 & 13 & 1.399 .976 & 20,81 & 50 & 0,340 & 3644 \\
\hline A roucória & 80 & GPS & 1.393 & 80 & 3.388 .274 & 041 & 60 & 0275 & 0262 \\
\hline Araucaria & 80 & $\mathrm{LBH}$ & 409 & 25 & 3.069 .288 & 9,41 & 00 & $0,2 / 2$ & 9202 \\
\hline Bom Jesus do & & GPS & 218 & 11 & 548.601 & & & & \\
\hline Sul & 11 & $\mathrm{LBH}$ & 68 & 7 & 518.094 & 5,56 & 40 & 0,255 & 160 \\
\hline Camno I aroo & 108 & GPS & 1.504 & 108 & 5.781 .506 & 2454 & 40 & 0300 & 33418 \\
\hline Campo Largo & 108 & LBH & 442 & 55 & 4.362 .844 & 24,54 & 40 & 0,300 & 33.418 \\
\hline & 52 & GPS & 2.711 & 52 & 7.553 .586 & & & & \\
\hline Castro & 52 & $\mathrm{LBH}$ & 739 & 37 & 7.012 .092 & $1,1 /$ & 40 & 0,222 & 28.394 \\
\hline Choninzinho & 38 & GPS & 1.234 & 38 & 4.042 .688 & 3355 & 60 & 0272 & 4176 \\
\hline Cnopinzinno & 38 & LBH & 359 & 21 & 2.686 .198 & 33,55 & 00 & $0,2 / 2$ & $4.1 / 0$ \\
\hline Cianorte & 30 & GPS & 983 & 30 & 3.918 .747 & 3207 & 40 & 0353 & 2383 \\
\hline Clanorte & 30 & $\mathrm{LBH}$ & 315 & 29 & 2.661 .866 & 32,01 & 40 & 0,353 & 2.383 \\
\hline & 50 & GPS & 979 & 50 & 3.153 .004 & & & & \\
\hline Cruz IMachado & 50 & LBH & 351 & 50 & 2.938 .034 & 0,82 & 20 & 0,242 & 1.148 \\
\hline Guaratuba & 25 & GPS & 708 & 25 & 1.324 .835 & 617 & 40 & 0347 & 5.786 \\
\hline Guaratuba & 25 & $\mathrm{LBH}$ & 165 & 24 & 1.243 .036 & 0,17 & 40 & $0,34 /$ & 5.180 \\
\hline & & GPS & 652 & 23 & 2.675 .360 & & & & \\
\hline Lapa & 23 & LBH & 227 & 18 & 2.316 .330 & 13,42 & 60 & 0,215 & 21.542 \\
\hline I oanda & 0 & GPS & 203 & 8 & 1.010 .582 & & & & \\
\hline Loanda & 9 & LBH & 77 & 8 & 918.270 & 9,13 & 30 & 0,291 & 116 \\
\hline Iondrina & 107 & GPS & 1.387 & 95 & 5.285 .160 & 3.44 & 40 & 0345 & 12626 \\
\hline Lonarina & 101 & $\mathrm{LBH}$ & 439 & 23 & 5.103 .538 & 3,44 & & 0,345 & 12.020 \\
\hline & & GPS & 395 & 23 & 1.792 .030 & & & & \\
\hline Marınga & 23 & LBH & 157 & 17 & 1.363 .788 & 23,9 & 30 & 0,290 & 868 \\
\hline Medianeira & 31 & GPS & 936 & 28 & 1.639 .964 & & & & \\
\hline Medianeira & 31 & LBH & 194 & 16 & 1.538 .722 & 6,17 & 30 & 0,338 & 1.538 \\
\hline Nova Prata do & 15 & GPS & 447 & 15 & 1.425 .522 & 773 & 30 & 0225 & 1178 \\
\hline Iguaçu & 15 & $\mathrm{LBH}$ & 170 & 14 & 1.315 .368 & 1,13 & 30 & $0,2 \angle 5$ & $1.1 / 8$ \\
\hline Ortiounira & 60 & GPS & 727 & 60 & 3.300 .498 & 21 & 60 & 0107 & 545 \\
\hline Ortigueira & 60 & LBH & 302 & 26 & 3.198 .114 & 3,1 & 60 & 0,191 & 2.545 \\
\hline Pitanga & 70 & GPS & 1.086 & 70 & 3.785 .790 & 392 & 40 & 0238 & 6.722 \\
\hline P1tanga & 70 & LBH & 621 & 42 & 3.637 .342 & 3,92 & 40 & 0,238 & 0.122 \\
\hline Ponta Grossa & 59 & GPS & 659 & 59 & 3.431 .116 & 773 & 50 & 0245 & 7.442 \\
\hline Ponta Grossa & 59 & $\mathrm{LBH}$ & 300 & 26 & 3.172 .732 & 1,13 & 50 & 0,245 & 1.442 \\
\hline Prudentónolic & 66 & GPS & 1.090 & 45 & 3.359 .002 & 364 & 40 & 0223 & $1140 ?$ \\
\hline Prudentopons & 00 & $\mathrm{LBH}$ & 375 & 26 & 3.236 .758 & 3,04 & 40 & 0,223 & 11.492 \\
\hline Outro Barras & 20 & GPS & 1.093 & 20 & 1.615 .827 & 785 & 40 & 0317 & 3045 \\
\hline Quatro Barras & 20 & LBH & 193 & 10 & 1.489 .006 & 7,85 & 40 & 0,317 & 3.045 \\
\hline RinNearo & 28 & GPS & 393 & 28 & 1.368 .813 & 2746 & 40 & 0299 & 1057 \\
\hline K10 Negro & 28 & $\mathrm{LBH}$ & 126 & 13 & 992.880 & 21,40 & 40 & 0,299 & 1.951 \\
\hline Sontr Amelis & 1 & GPS & 64 & 4 & 181.677 & 604 & 30 & 0260 & 5 \\
\hline Santa Amella & 4 & $\mathrm{LBH}$ & 30 & 4 & 169.066 & 0,94 & 50 & 0,209 & 5 \\
\hline Santa Helena & 34 & GPS & 967 & 34 & 1.699 .208 & 475 & 50 & 0254 & 1276 \\
\hline Santa Helena & 34 & $\mathrm{LBH}$ & 230 & 26 & 1.618 .500 & $4, / 5$ & 50 & 0,254 & 1.276 \\
\hline Santa Mariana & 12 & GPS & 137 & 12 & 801.693 & 1123 & 30 & 0207 & 98 \\
\hline Santa Mariana & 12 & LBH & 76 & 12 & 711.682 & 11,23 & 30 & 0,201 & 98 \\
\hline São Mateus do & 62 & GPS & 967 & 62 & 4.232 .140 & 1851 & 40 & 0257 & 7801 \\
\hline Sul & 02 & $\mathrm{LBH}$ & 230 & 41 & 3.448 .626 & 18,51 & 40 & 0,251 & 1.801 \\
\hline Toledo & 40 & GPS & 1.364 & 49 & 5.757 .980 & 1808 & 40 & 0230 & 11052 \\
\hline 1oledo & 49 & $\mathrm{LBH}$ & 461 & 46 & 4.664 .954 & 18,98 & 40 & 0,239 & 11.952 \\
\hline Tunas do & 8 & GPS & 294 & 8 & 1.126 .980 & 2272 & 50 & 0271 & 182 \\
\hline Paraná & 8 & LBH & 80 & 8 & 870.876 & 22,12 & 50 & $0,2 / 1$ & 182 \\
\hline Méd & & GPS & 890 & 38 & 2.759 .653 & & & & \\
\hline Media & & LBH & 265 & 24 & 2.365 .998 & 13,28 & 37,2 & 0,273 & 7.651 \\
\hline
\end{tabular}

